\title{
Health literacy of recently hospitalised patients: a cross-sectional survey using the Health Literacy Questionnaire (HLQ)
}

Rebecca L. Jessup ${ }^{1,2^{*}}$, Richard H. Osborne ${ }^{1}$, Alison Beauchamp ${ }^{1}$, Allison Bourne ${ }^{2,3}$ and Rachelle Buchbinder ${ }^{2,3}$

\begin{abstract}
Background: Health literacy is simply defined as an individual's ability to access, understand and use information in ways that promote and maintain good health. Lower health literacy has been found to be associated with increased emergency department presentations and potentially avoidable hospitalisations. This study aimed to determine the health literacy of hospital inpatients, and to examine if associations exist between different dimensions of their health literacy, sociodemographic characteristics and hospital services use.
\end{abstract}

Methods: A written survey was sent to 3,252 people aged $\geq 18$ years in English, Arabic, Chinese, Vietnamese, Italian or Greek. The survey included demographic and health questions, and the Health Literacy Questionnaire (HLQ). The HLQ is a multidimensional instrument comprising nine independent scales. Use of hospital services was measured by length of stay, number of admissions in 12 months and number of emergency department presentations. Effect size (ES) for standardised differences in means described the magnitude of differences in HLQ scale scores between demographic and socioeconomic groups.

Results: 385 questionnaires were returned (13\%); mean age 64 years (SD 17), 49\% female. Aged $\geq 65$ years (55\%), using the Internet < once a month (37\%), failure to complete high school (67\%), low household income (39\%), receiving means-tested government benefits (61\%) and being from a culturally and linguistically diverse (CALD) background (24\%), were all associated with lower scores in some health literacy scales. Being aged $\geq 65$ years, not currently employed, receiving government benefits, and being from a CALD background were also associated with increased use of some hospital services. There was no association between lower scores on any HLQ scale and greater use of hospital services.

Conclusion: We found no association between lower health literacy and greater use of hospital health services. However increased age, having a CALD background and not speaking English at home were all associated with having the most health literacy challenges Strategies to address these are needed to reduce health inequalities.

Keywords: Health literacy, Hospitalisation, Equity, Access

\footnotetext{
*Correspondence: rjessup@deakin.edu.au

'Deakin University, Health Systems Improvement Unit, Centre for Population Health Research, School of Health and Social Development, Geelong, Victoria 3220, Australia

${ }^{2}$ Monash Department of Clinical Epidemiology, Cabrini Institute, Malvern, VIC 3144, Australia

Full list of author information is available at the end of the article
}

\section{Bïomed Central}

(c) The Author(s). 2017 Open Access This article is distributed under the terms of the Creative Commons Attribution 4.0 International License (http://creativecommons.org/licenses/by/4.0/), which permits unrestricted use, distribution, and reproduction in any medium, provided you give appropriate credit to the original author(s) and the source, provide a link to the Creative Commons license, and indicate if changes were made. The Creative Commons Public Domain Dedication waiver (http://creativecommons.org/publicdomain/zero/1.0/) applies to the data made available in this article, unless otherwise stated. 


\section{Background}

The provision of safe, equitable and accessible health care is an ongoing challenge for all health service providers. In the face of increasing pressure from an ageing population $[1,2]$, growth in chronic and preventable disease [3], increasing healthcare costs and workforce shortages [4-8], and changing community expectations $[9,10]$ hospitals are under unprecedented pressure to deliver the right care, at the right time. An ongoing challenge for hospitals is the management of potentially avoidable hospitalisations for conditions that may have been treated or managed out of hospital [11]. While the reasons for requiring hospitalisation are complex and multifactorial, addressing a patient's health literacy needs may be one potential strategy for reducing avoidable hospitalisations.

Health literacy is defined by the World Health Organisation as the cognitive and social skills which determine the motivation and ability of individuals to gain access to, understand and use information in ways which promote and maintain good health' [12]. Individuals require good health literacy in order to access and understand all the information and support they require to appropriately manage unexpected acute illness or existing chronic conditions [13, 14].

Several studies have found an association between lower health literacy and potentially avoidable hospitalisations [15-17]. However these studies have generally used health literacy tools that are unidimensional, and only capture one aspect of health literacy, i.e. healthrelated reading $+/-$ numeracy ability [18]. As implied by the definition above and empirical data [19], health literacy is a multidimensional concept that cannot be fully captured by a single skill or attribute. The influence of contextual, social and cultural factors, and the ability of healthcare practitioners and healthcare organisations to meet patients' health literacy needs have received little attention.

The Health Literacy Questionnaire (HLQ) is a multidimensional instrument designed to generate a profile of an individual's or population's health literacy strengths and weaknesses [20]. It comprises 44 items across nine independent scales: Feeling understood and supported by healthcare providers; Having sufficient information to manage my health; Actively managing my health; Social support for health; Appraisal of health information; Ability to actively engage with healthcare providers; Navigating the healthcare system; Ability to find good health information; and Understanding health information enough to know what to do. In contrast to single dimensional measures, the HLQ has been demonstrated to provide a detailed profile of an individual's health literacy skills and needs. It has also been used to provide guidance for the development of interventions to address these needs [21], and therefore may also be useful to guide development of interventions to reduce avoidable hospitalisations. The aim of this study was to determine the health literacy strengths and weaknesses of a cohort of hospital inpatients, and to examine if associations exist between the different dimensions of health literacy and patients' demographic and socioeconomic characteristics and use of hospital services.

\section{Methods}

A cross-sectional survey was posted to patients who had recently (less than 30 days) attended an acute public hospital in Victoria, Australia. This hospital is located in Melbourne's northern suburbs and provides care to a diverse community. The hospital's catchment includes a higher proportion of people and households with lower income, lower educational attainment, higher numbers of migrants, and higher rates of unemployment than Victorian State averages [22]. The utilisation rates for hospital interpreter services identifies that over 120 languages are spoken amongst patients attending this service.

Data collection took place over six months from January to June 2015. Each month, 500 participants were invited to participate. Potential participants were identified through the hospital's computerized clinical and administrative data warehouse. Participants were eligible if they had been hospitalised for at least $24 \mathrm{~h}$ in the past 30 days, and if they spoke English, Arabic, Chinese, Vietnamese, Greek or Italian, all languages in the top 10 most spoken languages in the region. Participants were excluded if they had been hospitalised for less than $24 \mathrm{~h}$ to ensure that we excluded patients admitted for day medical procedures, day oncology, dialysis or those briefly attending emergency. Participants were also excluded if they were aged under 18, had a history of cognitive impairment, or if they were discharged to another institution rather than returning home. Each month, purposive sampling was used to identify all patients who spoke one of the non-English target languages to ensure oversampling of these groups. The remaining participants were randomly selected from eligible English speaking patients.

To maximise the survey response rate, each participant was sent a pre-notification letter written in their language and signed by the hospital's Chief Executive Officer (CEO). The letter encouraged participation in order to assist the hospital to improve services. A week later, participants were mailed the participant information and consent form, the HLQ and a brief survey of health and demographic and socio-economic variables in their language. A late return/reminder letter was sent two weeks following the mail out of the survey.

The study was approved by the Northern Health and Deakin University Human Research and Ethics Committees. 


\section{Hypotheses}

In keeping with previous studies, we hypothesised that being older, not speaking English at home, being born in a country where English was not the first language, and/or living alone would be associated with lower scores across all nine HLQ scales [21]. We also hypothesised an association between lower scores across the nine HLQ scales and lower socioeconomic status (unemployment, leaving school before completion, household income less than $\$ 30,000$, on government means tested benefits, not having private health insurance) and minimal Internet use (less than once a month).

With respect to use of hospital services, we hypothesized an association between lower health literacy and indicators of lower socioeconomic status and higher selfreported attendance at any hospital ED for non-urgent conditions in the previous 12 months, increased ED presentations for non-urgent conditions at the same hospital in the last 12 months, increased number of hospital admissions at the same hospital in the last 12 months, and longer length of stay for the index hospitalisation.

\section{Measures}

Health Literacy Questionnaire: The questionnaire takes between 7 and 40 min to complete [Jessup R, Beauchamp A, Buchbinder R, Osborne R: Psychometric properties and comparability of four health literacy assessment instruments in the hospital setting, submitted]. Each domain of the HLQ consists of either 4 or 5 items. Items in the first five domains are scored from 1 to 4 (strongly disagree $=1$ to strongly agree $=4$ ), while the last four domains are scored 1 to 5 (cannot do or always difficult $=1$ to very easy $=5$ ), A domain score is calculated by adding up the scores within each domain and then dividing this value by the number of items in the respective domain with higher scores indicating higher health literacy. Each HLQ domain has been demonstrated to be conceptually distinct and measure independent constructs using confirmatory factor analysis, consequently a total score is not generated [20].

The HLQ was translated from English into Arabic, Chinese (simplified, so it was suitable for both Cantonese and Mandarin speakers), Vietnamese, Italian and Greek as these 5 languages are in the top 10 most spoken languages in the region. The translation process consisted of forward, backward then forward translation, followed by further verification with native speakers to ensure that the intended meaning of items was consistent with the item intent.

Demographic and socioeconomic data: We collected data about age, sex, living arrangements (alone or with others), indigenous status, country of birth, primary language spoken at home (English or another language), educational attainment (completion of high school or not), work status (employed or not working (unemployed, retired, ill)), household income $(<$ or $\geq \$ 30,000$ per annum) and receipt of means-tested government benefits.
Use of hospital services: To examine use of services at the hospital where the research was based, we extracted service use information from the hospital's data warehouse for both respondents and non-respondents. Data extracted included: whether the admission was planned (or the patient was admitted via ED), the number of days they were hospitalised, number of hospital admissions at this hospital in the last 12 months (including the index one), and number non-urgent ED presentations to this ED in the last 12 months. In addition, we also asked respondents to self-report whether they had attended any ED at any hospital in the last 12 months.

\section{Statistical Analysis}

To determine whether an association between demographic and socioeconomic variables and hospital service use rates existed, we conducted Pearson chi-square tests using SPSS $^{\oplus}$ version 22 [23]. Effect sizes were calculated using the phi coefficient, a measure of the association between two binary variables, with a small effect size classified as being between 0.10 and 0.30 , a medium effect size from 0.30 to 0.50 , and large effect size $>0.50$ [24].

Cohen's effect sizes (ES) for standardised differences in means of HLQ scales across comparator variables were calculated using Stata ${ }^{\circ}$ software [25]. The pooled standard deviation (PSD) was used as the denominator and difference within scales as the numerator. In this case, the effect size describes the magnitude of differences in HLQ scale scores between groups, with scores between 0.20-0.50 considered small, 0.50-0.80 considered medium, and $>0.80$ considered large as described by Cohen [24]. A $p<0.05$ was regarded as statistically significant for all tests.

We assessed the relationship between use of hospital services and demographic and socio-economic characteristics and the key outcome variable, health literacy, with the aim of advancing to multiple regression analyses if an association was found between health literacy and use of hospital services.

\section{Results}

3252 surveys were sent and responses were received from 384 participants (response rate 13\%) (Fig. 1). The highest response was from participants completed the questionnaire in Chinese $(n=8 / 44,18.0 \%)$, followed by English $\quad(\mathrm{n}=307 / 1981,15.5 \%)$, Greek $(\mathrm{n}=18 / 171$, $10.5 \%)$, Italian $(\mathrm{n}=28 / 350,8.0 \%)$, Arabic $(\mathrm{n}=22 / 314$, $7.0 \%)$, and Vietnamese ( $\mathrm{n}=1 / 50,2.0 \%)$.

Table 1 displays the demographic and socioeconomic details, hospital services use and reason for admission of respondents, and non-respondents where available. The mean age of participants was 64 years (SD 17) and $49 \%$ were female. By comparison, mean age of non-respondents was lower (55 years (SD 21)) but the proportion of females 


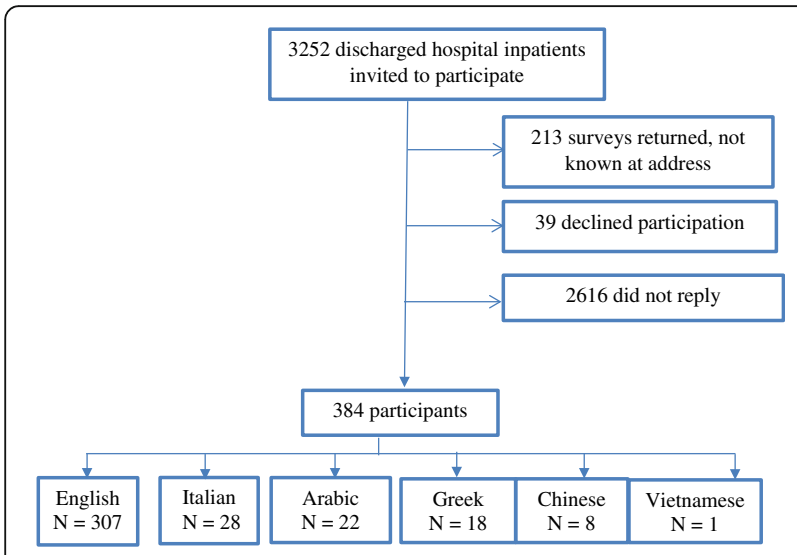

Fig. 1 Participant flow diagram

(51\%) was similar. Study participants were ethnically diverse and there were no indigenous participants, and they generally had low income and educational attainment. Seventy (23\%) lived alone, 144 (39\%) were born in a country where English was not the first language, 93 (25\%) did not speak English at home, and 258 (67\%) had not completed high school (including $80(21 \%)$ who completed a Trade qualification). Only 100 (26\%) were currently working in any capacity (full time, part time or casually). There did not appear to be any differences between respondents and non-respondents with respect to planned admissions (50/384 (13\%) versus 313/2616 (12\%)), median length of hospital stay ( 2 days (range 1 to 87 ) versus 2 days (range 1 to 54$)$ ), or reasons for admission.

Table 2 provides an overview of the mean HLQ scale scores for participants. For the overall sample, respondents reported highest scores for Feeling understood and supported by healthcare providers (mean 3.13, SD 0.57) and lowest scores for Appraisal of health information (mean 2.82, SD 0.52). There were no appreciable differences in health literacy scores or hospital service use according to completion of the survey in English or other languages.

Table 3 explores the relationship between sociodemographic variables and use of hospital services. Aged $\geq 65$ years was associated with being more likely to have had a hospital stay of greater than 7 days and to have two or more admissions in the last 12 months in the index hospital. Current unemployment was associated with being more likely to have two or more hospital admissions in the last 12 months in the index hospital. Lower economic status was associated with greater likelihood of two or more admissions in the last 12 months in the index hospital, having a hospital stay greater than 7 days and non-urgent ED presentations at the index hospital in the last 12 months. Not speaking English at home or coming from a non-English background was associated with a lower likelihood of self-reported non-urgent ED
Table 1 Demographic and socioeconomic characteristics of respondents and non-respondents and their health service use

\begin{tabular}{|c|c|c|}
\hline & $\begin{array}{l}\text { Respondents } \\
(N=384)\end{array}$ & $\begin{array}{l}\text { Non-respondents } \\
(N=2616)\end{array}$ \\
\hline & $N(\%)$ & $N(\%)$ \\
\hline \multicolumn{3}{|c|}{ Demographic and socioeconomic characteristics } \\
\hline Female & $188(49)$ & $1334(51)$ \\
\hline Age $\geq 65$ years & $211(55)$ & $1040(40)$ \\
\hline Lives alone $(6)^{a}$ & $70(18)$ & - \\
\hline Did not complete high school $(15)^{a}$ & $246(67)$ & - \\
\hline Born in English speaking country $(17)^{a}$ & $144(39)$ & - \\
\hline English spoken at home $(1)^{a}$ & $290(76)$ & - \\
\hline Currently employed $(10)^{a}$ & $98(26)$ & \\
\hline Receiving government benefits $(17)^{a}$ & $245(67)$ & - \\
\hline Private health insurance $(23)^{a}$ & $111(31)$ & - \\
\hline \multicolumn{3}{|l|}{ Hospital service use } \\
\hline Admission planned & $50(13)$ & $313(12)$ \\
\hline Length of stay $\geq 7$ days (2) ${ }^{a}$ & $61(16)$ & $348(13)$ \\
\hline $\begin{array}{l}\geq 2 \text { admissions in last } 12 \text { months } \\
\text { at this hospital }(2)^{\mathrm{a}}\end{array}$ & $343(90)$ & $2276(87)$ \\
\hline $\begin{array}{l}\text { Non-urgent ED presentations in } \\
\text { last } 12 \text { months at this hospital }(4)^{\text {a }}\end{array}$ & $103(27)$ & $680(26)$ \\
\hline \multicolumn{3}{|l|}{ Reason for admission } \\
\hline Maternity & $7(2)$ & $189(7)$ \\
\hline Gastrointestinal & $72(19)$ & $657(25)$ \\
\hline Cardiovascular & $72(19)$ & $320(12)$ \\
\hline Pulmonary & $45(12)$ & 199 (8) \\
\hline Urinary & $18(5)$ & $237(9)$ \\
\hline Musculoskeletal & $46(12)$ & $302(12)$ \\
\hline Gynaecologic & $9(2)$ & $61(3)$ \\
\hline Cellulitis & $10(3)$ & $79(3)$ \\
\hline Cancer & $10(3)$ & $82(3)$ \\
\hline Diabetes & $15(4)$ & $22(1)$ \\
\hline Delirium & $15(4)$ & $44(2)$ \\
\hline
\end{tabular}

${ }^{a}$ Missing data

presentation to any hospital in the last 12 months. Having private health insurance was associated with being slightly less likely to have self-reported non-urgent ED presentation to any hospital in the last 12 months, but being more likely to have had two or more hospital admissions in the previous 12 months in the index hospital.

Table 4 provides details of the associations between demographic and socio-economic characteristics and the nine scales of the HLQ. The largest differences in dimensions of health literacy were observed between participants speaking English or a language other than English at home. Compared to those who spoke English at home, speaking a language other than English at home was associated with reporting much greater difficulty 
Table 2 Health literacy and health service use of participants, all and by survey language $(\mathrm{N}=384)$

\begin{tabular}{|c|c|c|c|c|c|c|c|}
\hline & All $N=384$ & English $N=307$ & Arabic $N=22$ & Chinese $N=8$ & Greek $N=18$ & Italian $N=28$ & $\begin{array}{l}\text { Vietnamese } \\
N=1\end{array}$ \\
\hline & Mean (SD) & Mean (SD) & Mean (SD) & Mean (SD) & Mean (SD) & Mean (SD) & Mean \\
\hline \multicolumn{8}{|l|}{ Health Literacy Questionnaire (HLQ) } \\
\hline $\begin{array}{l}\text { Feeling understood and supported by } \\
\text { healthcare providers }\end{array}$ & $3.13(0.57)$ & $3.17(0.57)$ & $2.92(0.50)$ & $3.06(0.40)$ & $3.01(0.33)$ & $2.91(0.71)$ & 3.25 \\
\hline $\begin{array}{l}\text { Having sufficient information to manage } \\
\text { health }^{\mathrm{a}}\end{array}$ & $2.97(0.52)$ & $2.98(0.52)$ & $2.81(0.52)$ & $2.91(0.30)$ & $2.9(0.27)$ & $2.98(0.70)$ & 3.00 \\
\hline Actively managing my health ${ }^{a}$ & $2.93(0.52)$ & $2.93(0.52)$ & $2.87(0.53)$ & $2.95(0.54)$ & $2.93(0.34)$ & $3.05(0.61)$ & 2.80 \\
\hline Social support for health ${ }^{\mathrm{a}}$ & $3.11(0.55)$ & $3.12(0.55)$ & $3.08(0.46)$ & $2.93(0.59)$ & $3.19(0.43)$ & $3.06(0.66)$ & 2.80 \\
\hline Appraisal of health information ${ }^{a}$ & $2.82(0.52)$ & $2.81(0.52)$ & $2.93(0.47)$ & $2.9(0.44)$ & $2.89(0.42)$ & $2.83(0.67)$ & 3.00 \\
\hline $\begin{array}{l}\text { Ability to actively engage with health } \\
\text { care providers }\end{array}$ & $3.82(0.78)$ & $3.93(0.71)$ & $3.7(0.64)$ & $3.43(0.82)$ & $3.33(0.95)$ & $3.21(1.06)$ & 4.00 \\
\hline Navigating the healthcare system ${ }^{\text {b }}$ & $3.63(0.75)$ & $3.73(0.69)$ & $3.46(0.73)$ & $3.17(0.79)$ & $2.97(0.81)$ & $3.26(1.02)$ & 4.00 \\
\hline Ability to find good health information ${ }^{\mathrm{b}}$ & $3.56(0.80)$ & $3.67(0.73)$ & $3.44(0.77)$ & $3.33(0.87)$ & $2.65(0.99)$ & $3.14(0.95)$ & 3.20 \\
\hline $\begin{array}{l}\text { Reading and understanding health } \\
\text { information enough to know what to do }\end{array}$ & $3.85(0.78)$ & $3.97(0.67)$ & $3.85(0.72)$ & $3.28(1.00)$ & $3.21(0.89)$ & $3.19(1.12)$ & 3.00 \\
\hline \multicolumn{8}{|l|}{ Hospital service use } \\
\hline Length of stay, days & $4(8)$ & $5(9)$ & $4(5)$ & $3(2)$ & $5(4)$ & $5(5)$ & 1 \\
\hline $\begin{array}{l}\text { Number of hospital admissions in the } \\
\text { last } 12 \text { months at this hospital }\end{array}$ & $1(1)$ & $1(1)$ & $1(0)$ & $1(0)$ & $1(1)$ & $2(1)$ & 1 \\
\hline $\begin{array}{l}\text { Number of non-urgent ED presentations } \\
\text { in the last } 12 \text { months at this hospital }\end{array}$ & $1(4)$ & $1(4)$ & $0(1)$ & $0(1)$ & $1(1)$ & $1(3)$ & 0 \\
\hline
\end{tabular}

${ }^{a}$ Scale range $0-4$, higher score indicates greater ability or more support

${ }^{\mathrm{b}} \mathrm{S}$ cale range $\mathbf{0}-5$, higher score indicates greater ability or more support

Understanding health information enough to know what to do (ES 0.93 versus 0.65 ), poorer Ability to find good health information (ES 0.87 vs 0.73 ) and greater difficulty Navigating the health care system (ES 0.82 versus 0.70 ). Similar differences in mean scores on these scales were also observed between participants born in a country where English was or was not the first language. The scale that appeared most sensitive to detecting differences across sociodemographic characteristics was Ability to find good health information. We also found that those who rarely or never used the Internet reported finding it more difficult to Understanding health information enough to know what to do (ES 0.65) and poorer Ability to find good health information (ES 0.65). They also found it more difficult Navigating the health care system (ES 0.22) and Actively engaging with healthcare providers (ES 0.26).

Of the three conventional indicators of socioeconomic status (education, employment status and income), education showed the largest group differences for some variables. The only consistent finding across all three indicators was that participants with lower socioeconomic status reported more difficulty (lower scores) in Ability to find good health information (Education ES 0.38, Occupational Status 0.37 and Income 0.32). We found no relationship between any of the HLQ scales and private health insurance status.
There did not appear to be an association between greater use of hospital services and lower scores across any of the health literacy scales (Table 5). Having three or more hospital admissions at the index hospital in the past 12 months was associated with higher scores for Feeling understood and supported by healthcare providers and Social support for health, while a greater number of self-reported ED presentations in the last 12 months to any hospital was associated with higher scores for Active engagement with healthcare and Navigating the healthcare system. No differences in health literacy were seen based upon length of hospital stay ( $<7$ days vs $\geq 7$ days) or ED presentations ( $<2$ versus $\geq 2$ ED presentations). As no strong differences were found in these comparisons, multiple regression with adjustment for sociodemographic variables, was not undertaken.

\section{Discussion}

We identified a range of potentially modifiable health literacy needs in hospitalised patients. Consistent with our hypotheses, we found associations between increased age, coming from CALD background, having lower education and lower socioeconomic status, little use of the Internet and lower scores on some health literacy scales. Age, employment status, receiving means-tested government benefits and being from a CALD background were 
Table 3 Association between demographic and socioeconomic variables and hospital service use

\begin{tabular}{|c|c|c|c|c|}
\hline & $\begin{array}{l}\text { Self-reported presentation } \\
\text { to ED in last } 12 \text { months } \\
\text { (any hospital) }\end{array}$ & $\begin{array}{l}\text { Length of } \\
\text { stay } \geq 7 \text { days }\end{array}$ & $\begin{array}{l}\text { Two or more hospital } \\
\text { admissions in last } 12 \text { months } \\
\text { at this hospital }\end{array}$ & $\begin{array}{l}\text { Two or more non-urgent } \\
\text { ED presentations in last } \\
12 \text { months at this hospital }\end{array}$ \\
\hline & $\%$ & $\%$ & $\%$ & $\%$ \\
\hline \multicolumn{5}{|l|}{ Age } \\
\hline$<65$ years $(n=173)$ & 90 & $8^{\mathrm{a}}$ & $18^{\mathrm{a}}$ & 10 \\
\hline$\geq 65$ years $(N=211)$ & 92 & $16^{\mathrm{a}}$ & $33^{\mathrm{a}}$ & 13 \\
\hline \multicolumn{5}{|l|}{ Home living arrangement } \\
\hline Lives with others $(N=307)$ & 90 & 12 & 26 & 12 \\
\hline Lives alone $(N=70)$ & 97 & 16 & 24 & 13 \\
\hline \multicolumn{5}{|l|}{ Employment status } \\
\hline Currently employed $(N=113)$ & 91 & 7 & $17^{\mathrm{a}}$ & 11 \\
\hline $\begin{array}{l}\text { Currently not working (unemployed/retired/ill) } \\
(N=269)\end{array}$ & 91 & 15 & $30^{\mathrm{a}}$ & 12 \\
\hline \multicolumn{5}{|l|}{ Education } \\
\hline $\begin{array}{l}\text { Completed secondary education or } \\
\text { higher }(N=133)\end{array}$ & 93 & 13 & 28 & 11 \\
\hline $\begin{array}{l}\text { Did not complete secondary } \\
\text { education }(N=234)\end{array}$ & 91 & 13 & 24 & 17 \\
\hline \multicolumn{5}{|l|}{ Economic status } \\
\hline Household income $<\$ 30,000(N=149)$ & 93 & 15 & $31^{\mathrm{a}}$ & $17^{\mathrm{a}}$ \\
\hline Household income $\geq \$ 30,000(N=135)$ & 93 & 12 & $21^{\mathrm{a}}$ & $4^{\mathrm{a}}$ \\
\hline \multicolumn{5}{|l|}{ Receipt of means tested government benefits } \\
\hline No $(N=133)$ & 93 & $16^{\mathrm{a}}$ & $31^{\mathrm{a}}$ & 13 \\
\hline Yes $(N=234)$ & 90 & $8^{\mathrm{a}}$ & $17^{\mathrm{a}}$ & 8 \\
\hline \multicolumn{5}{|l|}{ Language in country of birth } \\
\hline $\begin{array}{l}\text { English (Australia, New Zealand, Britain) } \\
(N=219)\end{array}$ & $96^{\mathrm{a}}$ & 11 & 26 & 12 \\
\hline Non-English $(N=138)$ & $81^{\mathrm{a}}$ & 15 & 27 & 13 \\
\hline \multicolumn{5}{|l|}{ Language spoken at home } \\
\hline English $(N=283)$ & $96^{\mathrm{a}}$ & 12 & 26 & 11 \\
\hline Another language $(N=90)$ & $78^{\mathrm{a}}$ & 14 & 26 & 13 \\
\hline \multicolumn{5}{|l|}{ Use of internet } \\
\hline At least once a month $(N=218)$ & 93 & 10 & 25 & 12 \\
\hline Less than once a month or not at all $(N=139)$ & 90 & 15 & 31 & 13 \\
\hline \multicolumn{5}{|l|}{ Private health insurance } \\
\hline No $(N=249)$ & $96^{\mathrm{a}}$ & 9 & $16^{\mathrm{a}}$ & 8 \\
\hline Yes $(N=110)$ & $89^{a}$ & 14 & $30^{\mathrm{a}}$ & 13 \\
\hline
\end{tabular}

Variables in bold are significantly different between demographic or socioeconomic groups for hospital use (chi square tests $p<0.05$ )

${ }^{a}$ 'Small' effect size (ES) > 0.10-0.0.30 calculated using phi co-efficient

associated with increased use of some hospital services. However the data did not support our hypothesis, or previous studies $[15-17,26]$, that low health literacy would be associated with greater use of hospital services. On the contrary, we found that people with higher scores for two aspects of health literacy, Feeling understood and supported by healthcare providers and Social support for health were likely to be more frequent users of hospital services.
There is an extensive body of research that has demonstrated associations between being from a CALD background, lower health literacy, and health outcomes, including increased hospital utilisation [21, 27-31]. Being from a CALD background not only presents challenges for people in finding and understanding relevant and culturally appropriate health information and support in their language, but also presents challenges around differing health care delivery contexts. Our finding of an 


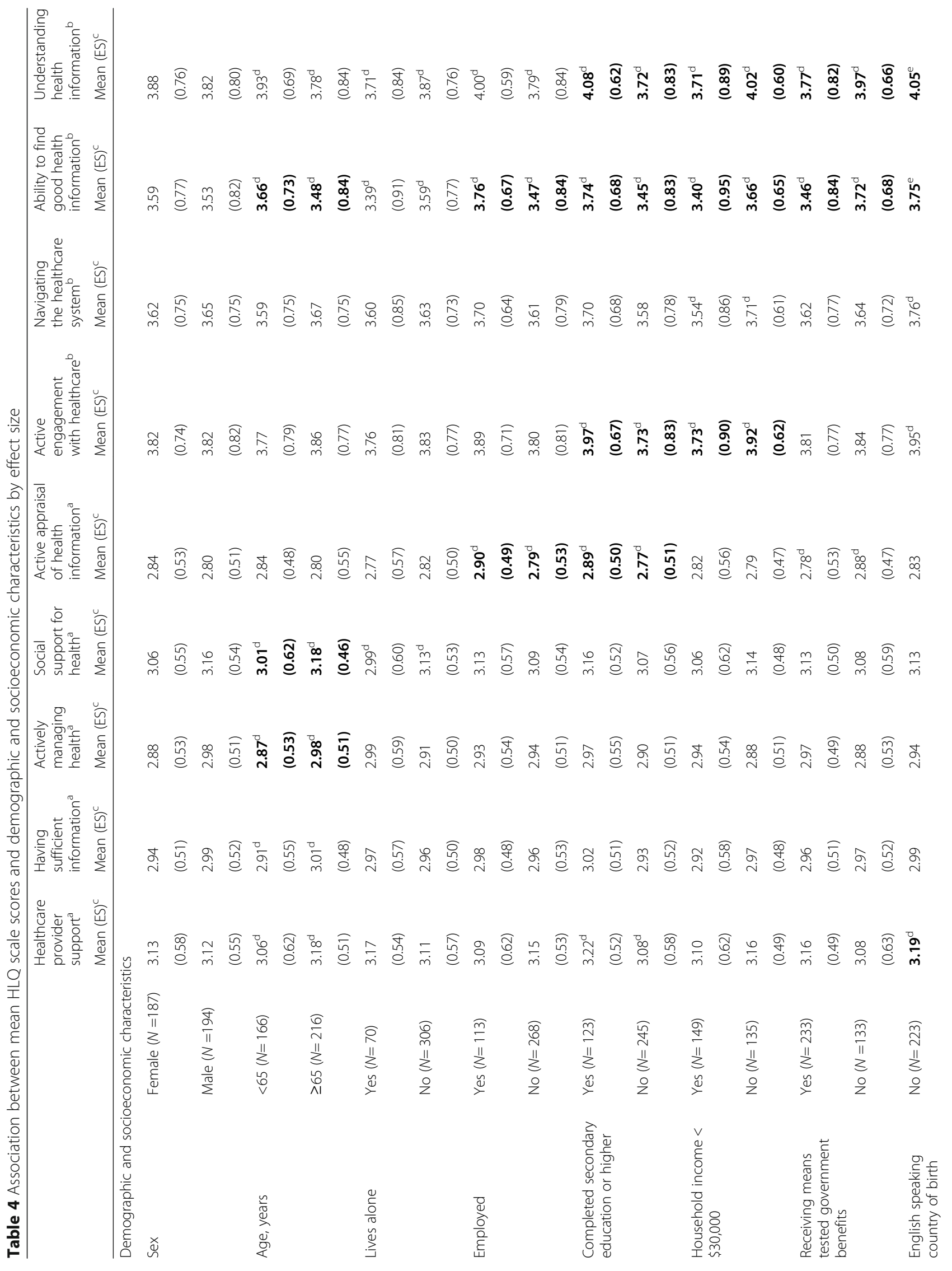




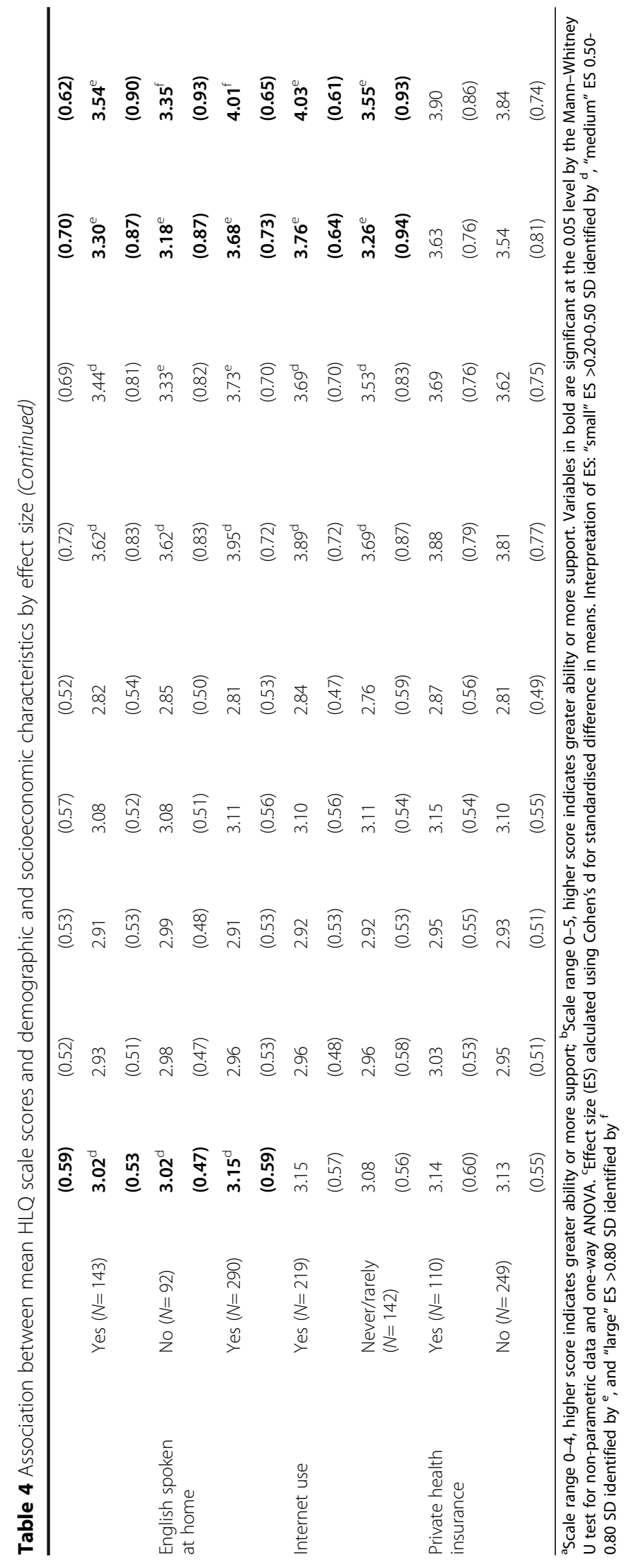




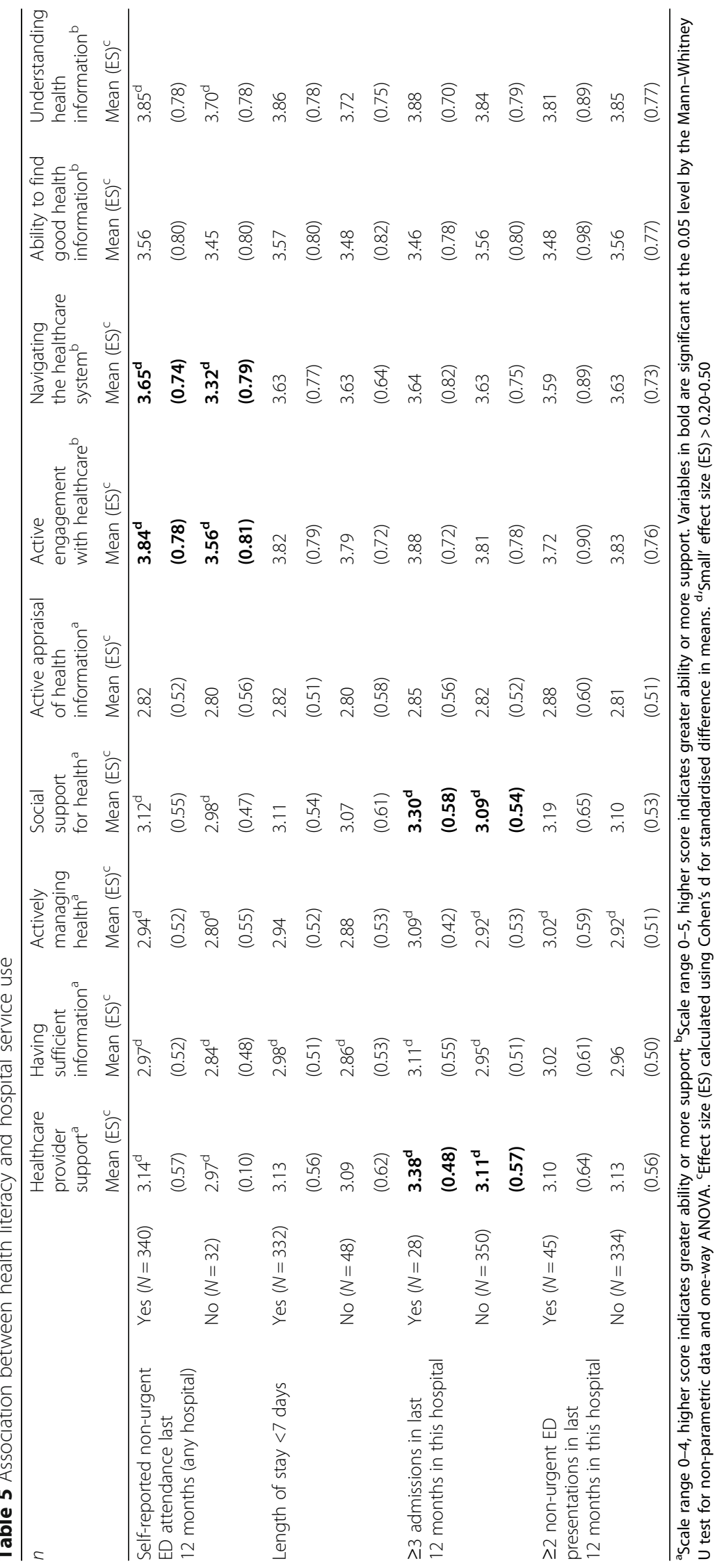


association between being born in a country where English was not the primary language and lower health literacy may correspond to differences in health care contexts (particularly pertinent for navigating the healthcare system), and differences in childhood opportunity, with these individuals likely to be migrants or descendants of migrants whose educational attainment and income opportunity may have been limited [32]. Our finding of an association between increased age, lower educational attainment and low socioeconomic status and lower health literacy is also in keeping with findings from previous studies [30, 31, 33-35]. However, unlike the prevailing literature [26-28], we did not find being from a CALD background was associated with increased use of hospital services - in fact we found that people from a CALD background were more likely to report less attendances at any ED over the last 12 month months.

Our finding of an association between older age, lower educational attainment and low socioeconomic status and lower health literacy is also in keeping with findings from previous studies [30, 31, 33, 35]. Our findings extend previous work by providing information on the relative strengths of these associations using effect sizes.

In contrast to previous studies [15-17], we did not observe an association between lower scores across any of the HLQ scales and higher use of hospital services. Several factors may explain these differences. We used a multi-dimensional self-report measure of health literacy whereas previous studies used functional health literacy tests that directly assess health-related reading, comprehension and numeracy. The correlation between these different measures has been found to be low. It is possible that the participants in our study, who all have free access to hospital services as part of the Australian healthcare system, are in an environment of high disease burden and overall low health literacy. It may also be that health literacy is irrelevant to individuals who require timely acute hospital-based care. As health literacy is a multidimensional concept, it may also be that looking for associations between individual scales of health literacy and use of hospital services is less relevant than considering an individual as a whole as strengths in some scales may offset limitations in other scales. Further investigation using different analytic techniques such as grouping individuals on the basis of specific health literacy levels may shed new light on these relationships.

Our study has several limitations. Our low response rate may limit the generalisability of our results to the broader hospitalised population, however we expect the data to have reasonable internal validity. Importantly, age, gender, reason for admission and use of hospital services were similar between respondents and nonrespondents, suggesting minimal response bias. Low response rates for mailed surveys in low socioeconomic populations show that those who return surveys are more likely to have higher socioeconomic indicators and health literacy [35-38]. This implies that our study may have underrepresented individuals with low and very low health literacy. While our data are internally valid, underrepresentation of people with low and very low health literacy may also have limited our ability to detect a relationship, if it exists, between health literacy and hospital services use. While availability of the HLQ in several languages likely improved the response rate from people with CALD backgrounds, with the exception of Chinese respondents, the response rate was still lower for these groups. Further, while care was taken in the translation of the HLQ to other languages, there is still some possibility that the intended meaning of items was conceptualised differently in groups from different cultures resulting in potential response bias [39]. Future research should consider alternative methods (such as face-to-face) for collecting data from CALD populations.

Our study also has some strengths. Use of the HLQ to measure health literacy provides insight across a broad range of domains of health literacy in addition to an individual's health-related reading, comprehension and numeracy skills, which has been the focus of many past studies utilizing functional health literacy instruments [35]. We also used Cohen's effect sizes to improve the understanding of the relative strength of associations. This information assists with making decisions about where health literacy interventions should be focused to have the largest impact.

This study has provided new insights into the complexity of health literacy, including not only an individual's skills in terms of finding, understanding and using health-related information but also their ability to navigate the health system and engage with health professionals, and their social supports. The HLQ embraces the full concept of health literacy by encompassing measurement of both a set of different individual skills and the lived experience of a person interacting with the services, systems and environment. These need to be considered together. For example, we found that increased age was associated with greater difficulty in finding health information, but older individuals were also more likely to report greater healthcare provider and social support than those under age 65 years. This suggests that social and health professional supports can offset other health literacy difficulties, while lack of these supports might indicate a need to provide additional assistance and resources.

\section{Conclusion}

Using a panel of nine fine-grained indicators of health literacy (the HLQ), this study did not find an association 
between lower health literacy and greater use of hospital health services. However we did find that increased age ( $\geq 65$ years), having a CALD background and not speaking English at home were all associated with having the most health literacy challenges, particularly around engaging with and feeling supported by health care providers, navigating the health system and finding and using health information. Strategies are needed that address these health literacy needs and should be evaluated to determine if they improve the quality of care and improve patient-relevant outcomes including reducing avoidable admissions. This type of approach may also reduce health inequalities.

\section{Abbreviations}

CALD: Culturally and linguistically diverse; ED: Emergency department; HLQ: Health Literacy Questionnaire

\begin{abstract}
Acknowledgements
The authors would like to thank the staff and patients of Northern Health for their support and participation in this study. Rebecca Jessup is funded by a National Health and Medical Research Council (NHMRC) PhD Scholarship \#1075250. Richard Osborne is funded in part by a NHMRC Senior Research Fellowship \#APP1059122. Alison Beauchamp is funded by an ARC Linkage Industry Fellowship. RB is funded by an NHMRC Senior Principle Research Fellowship \#APP1082138.
\end{abstract}

\section{Funding}

A Deakin University Higher Degree Research Grant assisted with the cost of postage of surveys for this study.

\section{Availability of data and materials}

The datasets generated during and/or analysed during the current study are available from the corresponding author on reasonable request.

\section{Authors' contributions}

The overall study and its design were devised by $\mathrm{RB}, \mathrm{RHO}, \mathrm{ABe}$. RJ performed the data collection, statistical analysis and drafted the manuscript. All authors contributed to the analysis strategy and interpretation of results and had extensive input into the manuscript. All authors approved the final draft.

\section{Competing interests}

The authors declare that they have no competing interests.

\section{Consent for publication}

Not applicable.

\section{Ethics approval and consent to participate}

This study was approved by the Northern Health (study no. P11/13, approved 20/05/2014) and Deakin University (study no. 2014-137, approved 10/06/2014). Human Research and Ethics Committees. Informed written consent was obtained from all participants. All data is de-identified so no consent to publish is required, however participants were informed of the intention to publish in the information and consent form.

\section{Author details}

${ }^{1}$ Deakin University, Health Systems Improvement Unit, Centre for Population Health Research, School of Health and Social Development, Geelong, Victoria 3220, Australia. ${ }^{2}$ Monash Department of Clinical Epidemiology, Cabrini Institute, Malvern, VIC 3144, Australia. ${ }^{3}$ Department of Epidemiology and Preventive Medicine, School of Public Health and Preventive Medicine, Monash University, Suite 41 Cabrini Medical Centre, 183 Wattletree Road, Malvern, VIC 3144, Australia.

Received: 14 September 2016 Accepted: 23 December 2016 Published online: 19 January 2017

\section{References}

1. Walker AS, University of Canberra. National Centre for, and M. Economic Australia's ageing population. Vol. no. 27. Canberra: National Centre for Social and Economic Modelling, University of Canberra; 1998.

2. Healey J. Ageing. Vol. 277. Thirrou: Spinney Press; 2008.

3. Australian Institute of Health and Welfare. Risk factors contributing to chronic disease. Canberra: Australian Institute of Health and Welfare; 2012.

4. Gordon B. Solving the workforce shortage. Health Prog. 2003;84(2):59.

5. Del Mar C. New investments in primary care in Australia. BMC Health Serv Res. 2011;11(1):39-9.

6. Brooks PM, Robinson L, Ellis N. Options for expanding the health workforce, Australian health review. publ Aust Hosp Assoc. 2008;32(1):156.

7. Buchan J, Naccarella L, Brooks P. Is health workforce sustainability in Australia and New Zealand a realistic policy goal? Australian health review. Publ Aust Hosp Assoc. 2011;35(2):152.

8. Australia's Health Workforce Productivity Commission Research Report. Canberra. 2005.

9. Hill S. The knowledgeable patient: communication and participation in health. West Sussex: Wiley-Blackwell; 2011

10. National Health Strategy. Health participation: achieving greater public participation and accountability in the Australian health care system. Melbourne. 1993. ISBN 0642191867

11. National Health Performance Authority. Healthy Communities: Selected potentially avoidable hospitalisations in 2011-12. Sydney: Commonwealth of Australia; 2013.

12. World Health Organization. Health Promotion Glossary. Health Promot Int. 1998;13(4):349-64.

13. Williams MV, Baker DW, Parker RM, Nurss JR. Relationship of functional health literacy to patients' knowledge of their chronic disease: a study of patients with hypertension and diabetes. Arch Intern Med. 1998;158(2):166-72.

14. Scott TL, Gazmararian JA, Williams MV, Baker DW. Health literacy and preventive health care use among Medicare enrollees in a managed care organization. Med Care. 2002;40(5):395-404.

15. Baker DW, Gazmararian JA, Williams MV, Scott T, Parker RM, Green D, Ren J, Peel J. Functional health literacy and the risk of hospital admission among Medicare managed care enrollees. Am J Public Health. 2002;92(8):1278-83.

16. Baker DW, Parker RM, Williams MV, Clark WS. Health literacy and the risk of hospital admission. J Gen Intern Med. 1998;13(12):791-8.

17. Mitchell SE, Sadikova E, Jack BW, Paasche-Orlow MK. Health literacy and 30-day postdischarge hospital utilization. J Health Commun. 2012;17(sup3):325-38.

18. Jordan J, Osborne RH, Buchbinder R. Critical appraisal of health literacy indices reveals variable underlying constructs, narrow content and psychometric weaknesses. J Clin Epidemiol. 2010;64(4):366-79.

19. Jordan JE, Buchbinder R, Osborne RH. Conceptualising health literacy from the patient perspective. Patient Educ Couns. 2010;79(1):36-42.

20. Osborne RH, Batterham R, Elsworth G, Hawkins M, Buchbinder R. The grounded psychometric development and initial validation of the Health Literacy Questionnaire (HLQ). BMC Public Health. 2013;13(1):658

21. Beauchamp A, Buchbinder R, Dodson S, Batterham RW, Elsworth GR, McPhee C, Sparkes L, M. Hawkins M, Osborne RH. Distribution of health literacy strengths and weaknesses across socio-demographic groups: a cross-sectional survey using the Health Literacy Questionnaire (HLQ). BMC Public Health. 2015;15(678):1-13.

22. State Government of Victoria. Index of Relative Socioeconomic Disadvantage. 2015 [cited 2015 February 23].

23. IBM Corp., IBM SPSS Statistics for Windows, Version 22.0. Armonk, NY Released 2013.

24. Cohen J. Statistical power analysis for the behavioral sciences (2nd Edition). Hillsdale: Lawrence Erlbaum Associates; 1988.

25. StataCorp, Stata Statistical Software: Release 14. College Station, TX, 2015

26. Cimasi RJ, Sharamitaro AP, Seiler RL. The association between health literacy and preventable hospitalizations in Missouri: implications in an era of reform. J Health Care Finance. 2013;WINTER:1-16.

27. Wolf MS, Knight SJ, Lyons EA, Durazo-Arvizu R, Pickard SA, Arseven A, et al. Literacy, race, and PSA level among low-income men newly diagnosed with prostate cancer. Urology. 2006;68(1):89-93. 
28. Bailey SC, Pandit AU, Yin S, Federman A, Davis TC, Parker RM, Wolf MS Predictors of misunderstanding pediatric liquid medication instructions. Fam Med. 2009;41(10):715-21.

29. Howard DH, Sentell T, Gazmararian JA. Impact of health literacy on socioeconomic and racial differences in health in an elderly population. J Gen Intern Med. 2006;21(8):857-61.

30. Sentell TL, Halpin HA. Importance of adult literacy in understanding health disparities. J Gen Intern Med. 2006;21(8):862-6.

31. Paasche-Orlow MK, Parker RM, Gazmarian JA, Nielsen-Bohlman LT, Rudd RR. The prevalence of limited health literacy. J Gen Intern Med. 2005:20(2):175-84.

32. Braveman PA, Cubbin C, Dgerter S, Chideya S, Marchi KS, Metzler M, Posner S Socioeconomic status in health research: one size does not fit all. JAMA. 2005;294(22):2879-88.

33. Gazmararian JA, Baker DW, Williams MV, Parker RM, Scott TL, Green DC, Fehrenbach SN, Ren J, Koplan JP, Fehrenbach SN, Ren J, Koplan J. Health literacy among Medicare enrollees in a managed care organization. JAMA. 1999;281(6):545-51.

34. Baker DW, Wolf MS, Feinglass J, Thompson JA, Gazmararian JA, Huang J. Health literacy and mortality among elderly persons. Arch Intern Med. 2007;167(14):1503-9.

35. Barber MN, Staples M, Osborne RH, Clerehan R, Elder C, Buchbinder R Up to a quarter of the Australian population may have suboptimal health literacy depending upon the measurement tool: results from a populationbased survey. Health Promot Int. 2009;24(3):252-61.

36. Fredrickson D, Jones T, Molgaard C, Carman C, Schukman J, Dismuke S, Ablah E. Optimal design features for surveying low-income populations. J Health Care Poor Underserved. 2005;16(4):677-90.

37. Gibson PJ, Koepsell TD, Diehr P, Hale C. Increasing response rates for mailed surveys of Medicaid clients and other low-income populations. Am J Epidemiol. 1999;149(11):1057-62.

38. Beebe TJ, Davern ME, McAlpine DD, Call KT, Rockwood TH. Increasing response rates in a survey of Medicaid enrollees: the effect of a prepaid monetary incentive and mixed modes (mail and telephone). Med Care. 2005:43(4):411-4.

39. Warnecke RB, Johnson TP, Chavez N, Sudman S, O'rourke DP, Lacey L, Horm J. Improving question wording in surveys of culturally diverse populations. Ann Epidemiol. 1997;7(5):334-42.

\section{Submit your next manuscript to BioMed Central and we will help you at every step:}

- We accept pre-submission inquiries

- Our selector tool helps you to find the most relevant journal

- We provide round the clock customer support

- Convenient online submission

- Thorough peer review

- Inclusion in PubMed and all major indexing services

- Maximum visibility for your research

Submit your manuscript at www.biomedcentral.com/submit

) Biomed Central 